\title{
The Yngve Ericsson Prize: Progress in Prophylactic Dentistry Research Awarded
}

The 2016 Yngve Ericsson Prize for Research in Preventive Odontology has been awarded jointly to Professor Jo Frencken of Radboud University, Nijmegen, the Netherlands, and Professor Panos Papapanou of Columbia University, New York, NY, USA. The Prize of SEK 400,000 (approx. EUR 43,000) is to be shared equally between the two recipients and will be awarded at the ORCA Congress in July in Athens, Greece.

Jo Frencken, Associate Professor Emeritus in Minimal Intervention Dentistry at the College of Dental Sciences of the Radboud University Medical Centre in Nijmegen, is a public health specialist by training. His early experience, in Malawi, Africa, of the many facets of oral health in the absence of regular dental care significantly altered his perception on how dental caries might be managed, and this led him to reconsider how oral care can be made available for an increasing number of people and communities. Dr. Frencken's research has thus mainly focused on caries prevention and on providing dental care by principles that were earlier deemed less justifiable but currently considered as valid, given the fact that low-income populations cannot afford the well-known standards of oral care. He pioneered the development of the ART (atraumatic restorative treatment) concept and was instrumental in researching the many aspects of this min-

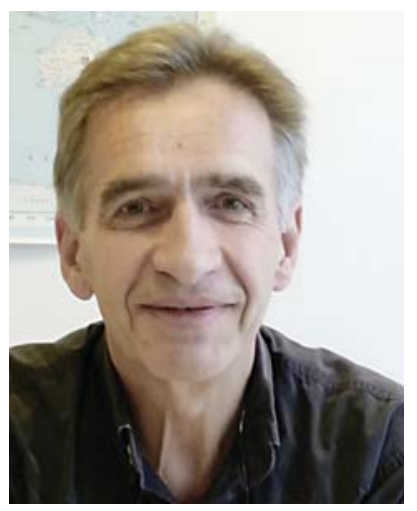

Jo Frencken

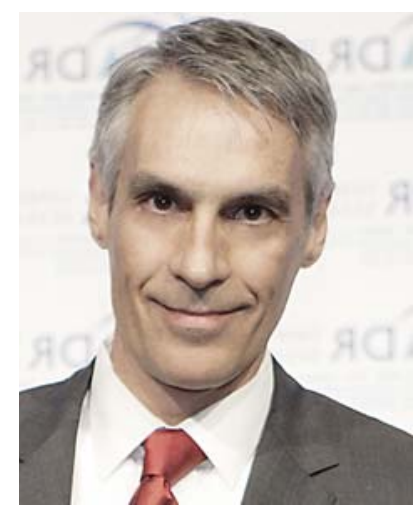

Panos Papapanou imal intervention dentistry concept. His latest line of research has resulted in the development of a novel carious lesion assessment and treatment instrument (CAST) for use in epidemiological studies. Dr. Frencken's solid and highly dedicated research has contributed greatly to the prevention of dental diseases and to increasing the accessibility of oral health care for many individuals and population groups in different countries worldwide.

Panos Papapanou is Professor of Dental Medicine, Director of the Division of Periodontics, and Chairman of

\section{KARGER}

E-Mail karger@karger.com www.karger.com/cre
(C) 2016 S. Karger AG, Basel

0008-6568/16/0503-0346\$39.50/0 
the Section of Oral, Diagnostic and Rehabilitation Sciences at the College of Dental Medicine, Columbia University, New York, NY, USA. He has earned DDS degrees from the University of Athens, Greece, and Columbia University, NY, USA, and a PhD from the University of Gothenburg, Sweden, and has received postdoctoral training in oral microbiology at the Forsyth Institute, Boston, MA, USA. Dr. Papapanou is the recipient of several international awards, most recently the William Gies Award for Clinical Research from the IADR in 2015. He is a board member of several scientific journals, Fellow of the American College of Dentists, and Past President and Councillor of the Periodontal Research Group of the IADR. Dr. Papapanou's research has been funded by the National Institutes of Health and encompasses studies of the epidemiology of periodontal disease, the assessment of microbial and host-derived risk factors, and the pathobiology of periodontitis and its role in general health. He has published a considerable volume of scientific articles related to clinical and preventive aspects of periodontal disease in well-recognized scientific journals, the results of which form a solid basis for the understanding of preventive odontology measures.

The Yngve Ericsson Prize is awarded once every 3 years in acknowledgement of outstanding contributions to the prevention of oral diseases. Established in 1963, the Swedish Patent Revenue Fund for Research in Preventive Odontology (www.pmf.se) was originally founded on royalties from patents, primarily patents for the addition of fluoride to dentifrices to prevent or arrest dental caries. The fund is the largest non-public granting source for dental research in Sweden through its continued support of research into the prevention of dental and oral diseases. This international prize is named after its founder.

The prize awardees have been selected by a five-member Prize Committee appointed by the Patent Revenue Fund and ORCA - the European Organization for Caries Research. The prize will be presented on July 7, 2016 at the ORCA Congress in Athens, Greece.

For further information, please contact:

Anders Linde, Professor at the Sahlgrenska Academy, University of Gothenburg, Sweden, President of the Patent Revenue Fund and Chairman of the Prize Committee. E-Mail: linde@odontologi.gu.se; Tel. +46-31-7863386

Vita Maciulskiene, Professor at the Lithuanian University of Health Sciences, Kaunas, Lithuania, President of ORCA and Member of the Prize Committee. E-Mail: Vita.Maciulskiene@lsmuni.lt; Tel. +370-37-326919 